\title{
Exploring consumers' willingness to pay for online customisation and its marketing outcomes
}

Received (in revised form): 15th July, 2002

\section{Pingjun Jiang}

was awarded her PhD in marketing from Southern Illinois University at Carbondale in December, 2001. Currently she is working as an instructor at the Department of Marketing, College of Business Administration, Columbus State University, Columbus, USA. Her fields of specialisation are marketing research methodology, relationship marketing, marketing management and consumer behaviour on the Internet. Her research has appeared in the Journal of Internet Research, Journal of Segmentation in Marketing and AMA (2000 and 2001) Proceedings.

\begin{abstract}
This paper investigates several issues surrounding online mass customisation via an analysis of consumer 'willingness to pay for customisation' and its strategic relationship with other marketing outcome variables (eg confidence in decision making, customer anticipated satisfaction and revisit intention). Contrary to expectations, it is found that consumers are not willing to pay more for the additional economic benefits they gain from customisation. In a customisation scenario, however, consumers more willing to pay for customisation per se would be more confident in their purchase choice, more likely to be satisfied with the chosen product/service/information and more likely to revisit the customisation provider. Therefore, the exploration into 'willingness to pay for customisation' leads to important managerial implications for marketers.
\end{abstract}

\section{INTRODUCTION}

One of the most interesting opportunities when introducing e-commerce in business-to-consumer networks is that the new information technology structure may be used to empower consumers to be more active participants in the economic value creation process. ${ }^{1,2}$ Consumers may, for example, create their own personalised version of a website or services, or communicate with other consumers about products they have bought. Many Internet-based firms have recognised the potential benefits of these opportunities and are encouraging various types of 'one-to-one targeting' strategies. Technology, especially the combination of flexible manufacturing and
Internet-based information and communication technology has altered the traditional product development process and production process by being able to incorporate consumer tastes or preferences throughout the product development period. This is most prominent in the emerging strategy of mass customisation, which has unleashed a wave of changes in several industries (eg Dell.com in the computer industry).

In addition to requiring an improved consumer-to-supplier information flow, an online customisation strategy also will have an impact on more traditional supplier-to-consumer marketing communication. Firms are realising that more and more consumers have 
information about the product solutions that they require and that firms will have to devise means to elicit such information from them. Firms then have to provide products that satisfactorily incorporate the consumer suggestions thus elicited. Despite its growing popularity in marketing practice and the attention it has received in the trade press, co-opting consumer competence has, however, hardly been investigated in the academic literature.

This research is interested in answering the following questions:

— what is consumers' willingness to pay for customisation

- are there any strategic implications for marketing outcomes, if consumers are willing to pay more for a customised product

- in what way does 'willingness to pay for customisation' relate to those marketing outcome variables? For example, confidence in decisionmaking, customer anticipated satisfaction and revisit intention?

The main objective of the paper is to bring into focus the issues surrounding online mass customisation via an analysis of consumer 'willingness to pay for customisation' and its strategic relationship with other marketing outcome variables. Moreover, it addresses the important question of the impact of customisation on marketing which, as Wind and Rangaswamy ${ }^{3}$ have pointed out, is a topic that is still under-researched, in contrast to the impact of customisation on manufacturing.

Online customisation can create two main types of economic benefits for consumers by allowing them to participate more actively in 'coproducing' a product/service/ information. First, consumers can assist producers in achieving lower production costs and creating higher consumption utility for the consumer's own benefit (eg by lowering transaction costs or by allowing producers to make more customised products). Secondly, the Internet can be a vehicle through which consumers can generate additional value for themselves, directly and without business intermediation (eg by providing suggestions for new product designs or by sharing information about their preferences).

From a firm's point of view, the success of implementing online customisation will depend on consumers' willingness to pay for such additional benefits. Are consumers willing to pay for the above economic benefits? Little is known about the answer. The current study analyses the likelihood of the consumer choice to pay to Internet websites for customisation. In addition, based on variety literature ${ }^{4}$, hypotheses are formulated on the relationships between consumers' willingness to pay and marketing outcome variables. Finally, the validity of these hypotheses is explored drawing on data collected online.

\section{WILLINGNESS TO PAY FOR CUSTOMISATION}

The study by Godek et al. ${ }^{5}$ showed that 'willingness to pay for product' is a useful construct that contributes to explaining the effects of customisation. Customisation evokes both positive and negative influences that are understood to be antecedent influences on willingness to pay for it. Though much attention has been paid to measures of 'willingness to pay for product', 6 this research examines 'willingness to pay for customisation' per se, and its role as an antecedent of marketing outcome variables. 
The 'willingness to pay for customisation' involves the money added to a product/service by consumers' associations and perceptions of customisation to obtain such a product/service/information. It is intuitively sensible that consumers will have more favourable general reactions to pay for customisation per se that they get additional benefits.

Hypothesis 1: In general, as opposed to wanting customisation provided at no charge, consumers are willing to pay extra charge for online customisation.

\section{MARKETING OUTCOME VARIABLES}

One of the few studies that have addressed marketing outcomes of customisation is by Huffman and $\mathrm{Kahn}^{7}$ who have approached mass customisation from the consumers' viewpoint. They have shown that the way information is presented and the type of consumer input to the information-gathering process influence consumer satisfaction. In particular, they show that consumers are more satisfied when they are asked to indicate explicitly their preferences for attributes, as compared to more effortful or less effortful tasks.

According to Prahalad and Ramaswamy, ${ }^{8}$ customisation assumes that the manufacturer will pre-design a product so as to suit the needs of different consumers. This could happen when the manufacturer forces the consumer to choose from a pre-determined menu of features. For example, if a consumer has to choose from a menu of features, then many concerns about their willingness to pay for customisation are raised. This is the case because customisation is putting together features whose amounts and quality can match better with consumers' preferences. If there is processing or value addition to be done by the manufacturer after the consumer's input, and incorporating that input, then there are serious questions about their willingness to pay for customisation. This is so because the final product comes into existence after the consumer has already provided input which, in some cases, could be quite costly for the consumer. The consumer would of course want to ensure that the final product successfully incorporates his or her input.

Expectation is a traditional measure of marketing effectiveness that provide marketers with a method to assess whether the value was delivered and whether it was absorbed into a consumer's belief (attitude) system. Disconfirmation theory suggests that customer expectation is likely to be higher when customers actually put in more effort than they expect to expend in purchase decision making. In online customisation, customers have more control by interacting with marketers than non-customisation context. Since they are more involved in the purchase process, they might have higher expectations about the customisation. Wind and Rangaswamy ${ }^{9}$ point out that one of the key challenges of customisation is that it creates higher consumer expectations as compared to more traditional processes. As consumers become more sophisticated and demanding, broadly confirmed within the futures literature, ${ }^{10}$ expectations about customisation as well as products/services are increasing.

Furthermore, the electronic marketplace is distinct from the traditional retailing format in that more information can be made available at the point of purchase. Some websites have multiple layers of Web pages with 
detailed information for customising. Customers will value customisation when more detailed effort is needed. When surfing through the Web pages with multi layered and rich information, customers will tend to value the customisation experience more than when the information is very superficial. ${ }^{11}$ Good information content also helps customers make more informed decisions, thereby increasing the confidence in their choice. Just as the confidence in purchase decision of a customer who buys a suit off the shelf are far lower than those of the customer who buys a custom-tailored suit, the customisation process creates higher confidence in the chosen product/service. Consumers are confident in the products they receive to match perfectly their needs and wants.

\section{Choice confidence}

Choice confidence is a consumer's certainty about the chosen product/service from customisation, and it reflects the likelihood of this consumer making a purchase of this product/service.

According to Huffman and Kahn, ${ }^{12}$ many retailers (especially e-tailers or e-sellers) have moved toward strategies that use large assortments and/or customisation in order to establish a competitive advantage. Unfortunately, these high-variety strategies can have negative consequences for the consumer who becomes confused or frustrated in the buying process. Category killers such as Circuit City, for example, may find that consumers who are simply shunted from one alternative to another find learning difficult and experience significant frustration. These frustrated consumers may have less confidence in their choices, therefore delay purchasing, or worse, choose not to buy at all.
On the other hand, people are more likely to defer a decision when the choice between $X$ and $Y$ is difficult (eg when the alternatives are about equally attractive but not identical) than when the choice is easy (eg when $X$ dominates $Y) .{ }^{13}$ As suggested by their results, choice may be even more difficult when $X$ and $Y$ are described by a set of unique features. A deferred decision should be more likely to happen, and people should be more resolute about the deferred decision, when choice options have non-alignable features rather than alignable features. ${ }^{14}$ In such a case, participants are more likely to undergo a less satisfying experience when conducting feature comparison due to non-alignable differences of the alternatives in addition to decisions between alternatives that are relatively similar in attractiveness. When the choice process results in ease of comparison and perceived sufficient amount of information, it will provide an environment that is more likely to foster a decision-seeking attitude and strengthen the choice confidence. ${ }^{15}$

Marketers can mitigate for customers the frustration associated with information overload. Huffman and $\mathrm{Kahn}^{16}$ show that a significantly greater percentage of the attribute-based subjects were ready to make a choice relative to the subjects who saw the information in an alternative-based format. At the same time, these results are likely to hold for the customisation process. For example, when alternatives are customised by attributes or bundles of attributes, consumers may be less overwhelmed, therefore can take full advantage of the available information to fulfil their desires more precisely. By doing so, they will be more willing to pay for the customisation, and more confident in their choices. 
Hypothesis 2: Choice confidence is positively related to willingness to pay for customisation, greater willingness to pay corresponds to higher choice confidence.

\section{Anticipated satisfaction}

Anticipated satisfaction is the consumer's assessment of the likely satisfaction with consuming his/her chosen product/service. This construct is conceptually related to MacInnis and Price's ${ }^{17}$ notion of pre-consumption mental imagery, where the consumer vicariously experiences the satisfaction of consuming a product prior to actual consumption.

People encountering overly extensive choices use a choice-making heuristic that necessarily leads them to feel less committed to exercising their preferences. Previous research has argued that limited-choice contexts invite people to engage in rational optimisation - to try to decide which option in a set is the single best one for them, which indicates a higher willingness to pay more, and a higher likelihood of being satisfied with consuming the choice.

By contrast, choosers in extensive-choice contexts may endeavour to balance the trade-offs between accuracy and effort, adopting simplifying heuristic strategies that are much more selective in their use of available information. ${ }^{18-21}$ Consequently, extensive-choice contexts may invite people merely to 'satisfice' to stop when they find any choice that seems acceptable. ${ }^{22-24}$ In other words, when people have 'too many' options to consider, they simply strive to end the choice-making ordeal by finding a choice that is merely satisfactory, rather than optimal. Similarly, choosers opting to satisfice in extensive-choice contexts should also report less willingness to pay more and less likely to expect to be satisfied with their particular choices.
More importantly, the previous results ${ }^{25}$ also showed that for high-variety assortments, the customisation format reduces perceived complexity, increases satisfaction with the process, and facilitates consumers' willingness to make a choice. Thus,

Hypothesis 3: Anticipated satisfaction is positively related to willingness to pay for customisation, greater willingness to pay for customisation corresponds to higher anticipated satisfaction.

\section{Revisit intention}

The most striking result is that online customisation has a positive impact on intention to revisit. Online customisation is designed to provide options that appeal to every consumer taste. The advantage of this type of strategy is that marketers can provide a product that uniquely fits consumer needs, and perhaps do so in such a way as to ensure strong intention to revisit.

This suggests that online customisation induces 'stickiness' that encourages customers to remain with the service, as compared to the traditional retailing format. One reason for this stickiness is that once a customer makes a purchase choice and interacts with the customisation provider through information exchange, s/he can more easily choose the service provider repeatedly (through revisiting the same e-tailer/e-seller). This is because customising a product at the same time is a co-producing process of consumers and marketers. This in turn might make consumers' attitudinal disposition towards that customisation provider stronger (ie creates 'cognitive stickiness'). The stickiness features thus create a deeper commitment to revisit the same customisation provider.

Furthermore, the customisation may 
allow for further positive reinforcement through learning more from and being more frequently exposed to the marketers. This result appears to be consistent with the prediction of transaction cost theory in this context. According to Williamson ${ }^{26}$, the cost of exchange will be easier to recover for large transactions of a recurring kind. Thus, a higher intention to revisit is expected due to this factor.

Through multiply revisiting the customisation provider, customers are gaining the co-producing ability by describing more exactly what they want, and marketers are gaining the information to fulfil better. Because customisation provides unparalleled information on customer behaviour, smart marketers can more rapidly adapt their offerings to the customer's changing needs. For return users, familiarity with a customisation process allows them to pick up options with less effort by taking advantage of knowledge gained in the previous purchase. When the consumer learns to 'trust' the customisation provider after experiencing it once, this does not only manifest itself on the next occasion in less effort or better choice selected but also in the ability to maintain the same level of cognitive cost and quality of selection at an even lower price. One good example of successful marketing through customisation is Barbie.com. Customers now can create their own customised Barbie by giving her a unique skin colour, eye colour, name, wardrobe and even a printed-out life story. Barbie has struck this creative marketing strategy by keeping customers coming back for more over a lifetime.

Furthermore, customisation facilitates easier comparison of alternatives. The ease of obtaining information is also typically higher in customisation than any other shopping contexts, especially for products with a lot of functional attributes, like computers. Easier access to information typically increases the tendency to repeat choices. Thus,

Hypothesis 4: Revisit intention is positively related to willingness to pay for customisation, greater willingness to pay corresponds to the customers' higher intention to revisit.

\section{RESEARCH DESIGN}

The research experiment is designed to determine empirically the willingness to pay for customisation (H1) and test the hypothesised relationships above $(\mathrm{H} 2-\mathrm{H} 4)$. The first hypothesis (H1) deals with the main effects of the one-to-one targeting on willingness to pay for customisation. The second set of hypotheses $(\mathrm{H} 2-\mathrm{H} 4)$ investigates marketing outcomes of willingness to pay for customisation in terms of choice confidence, anticipated satisfaction and revisit intention.

\section{Stimuli}

For products whose attributes are primarily utilitarian, consumers may decide to merely add the relative pros and cons of each feature. For example, a television or a computer may be evaluated in this manner to determine if it offers the highest summative value. In this sense, a verbal description of each feature of this product may be sufficient for a consumer to reach a decision. Products of this type are easy to customise.

Customisation is operationalised through asking the consumer which level $\mathrm{s} /$ he prefers for each attribute of the product or service and then a customised product is developed based on those preferences. An example of this method is the one used by Dell Computers on their website. In Dell's case, components of computers might be considered as the 
various attributes, and consumers are able to search through and select one of the various offerings of each type of component (eg central processor, hard drive, memory, etc.) that might go into their computers. Dell then aggregates all of the individual attribute selections and builds a customised computer that is then presented to the consumer for approval prior to purchase.

The historical success of Dell's online customisation strategy has made the computer the most popular product being customised at Internet websites (eg www.compaq.com). Correspondingly, the computer also becomes the favourite product for academicians to conduct their customisation studies. ${ }^{27}$ It is for this reason that the laptop computer product is selected and tested in this study. As stated above, this product is chosen for the reason of its balance of easy customisability, and comparatively high degree of familiarity to most American consumers and customising expertise among ordinary consumers within the product category.

The decision tasks chosen for the experiment are the selection of an affordable and most preferable laptop computer. The stimulus presentation and data collection via computer are used. All possible combinations of laptop computer selections are made available in the customisation process. All product attributes for attribute-based customisation are mostly selected from popular shopbots (Internet-based services that provide 'one-click' access to price and product information from numerous competing retailers) and computer manufacturers' websites. A detailed description of the stimuli used is contained in Table 1.

\section{Online data collection}

Participants are solicited using both online and traditional media. These include announcements placed on Internet-related newsgroups, chat rooms and announcements made in high exposure sites. Participants are contacted randomly via e-mail and asked to complete the current experiment voluntarily on the World Wide Web. One hundred and eight respondents comprise the final analysis sample. The survey employs non-probabilistic sampling and self-selection, and it is not representative of the general population of Web users. The final instrument is administered as a Web fillout form that is posted from June to July, 2002.

Subjects are noticed to the Web address and exposed to the customisation condition. The subjects are presented with a cover story in which a national computer company wants consumer input for designing their products to be offered in the near future, and then subjects are asked to examine carefully as much information as they need about each attribute of processor, speed, RAM, Max RAM, hard drive, display size, colour depth, resolution, CD/DVD, Operating System (OS), input, colour, weight and brands. They would be able to build their own laptop computer type by making choices on each of the above attributes at their discretion. After making their selection, subjects are asked to complete a questionnaire containing the measures of willingness to pay for customisation, choice confidence, anticipated satisfaction and revisit intention (as shown in Figures 1-4).

\section{Instrument: scale development process}

The measures used in this study reflect a series of newly developed scales. The survey instrument is developed on the basis of pilot scale testing. The model tested in this research has four measurable constructs. All the four constructs are operationalised using 
Exploring consumers' willingness to pay for online customisation and its marketing outcomes

Table 1: The customisation attribute-level descriptions for laptop computer

\begin{tabular}{|c|c|}
\hline Attribute & Attribute description \\
\hline Processor & $\begin{array}{l}\text { Any processor (by default), Celeron, Celeron A, K6 MMX, K6-2, MediaGXm, Pentium II, } \\
\text { Pentium III, Pentium MMX, PowerPC } 603 \mathrm{e} \text {, PowerPC } 603 \mathrm{ev} \text {, PowerPC G3 }\end{array}$ \\
\hline Speed & Any speed (by default), $200 \mathrm{MHz}, 300 \mathrm{MHz}, 400 \mathrm{MHz}, 500 \mathrm{MHz}, 600 \mathrm{MHz}, 700 \mathrm{MHz}$ \\
\hline RAM & Any RAM (by default), 16 MB, 32 MB, 64 MB, 96 MB, 128 MB, 192 MB, 256 MB \\
\hline Max RAM & $\begin{array}{l}\text { Any Max RAM (by default), } 64 \mathrm{MB}, 80 \mathrm{MB}, 96 \mathrm{MB}, 128 \mathrm{MB}, 144 \mathrm{MB}, 160 \mathrm{MB}, 192 \\
\mathrm{MB}, 256 \mathrm{MB}, 288 \mathrm{MB}, 320 \mathrm{MB}, 384 \mathrm{MB}, 512 \mathrm{MB}, 544 \mathrm{MB}, 576 \mathrm{MB}, 256 \mathrm{~TB}\end{array}$ \\
\hline Hard drive & $\begin{array}{l}\text { Any hard drive (by default), 1.0 GB, 2.0 GB, 3.0 GB, } 4.0 \mathrm{~GB}, 5.0 \mathrm{~GB}, 6.0 \mathrm{~GB}, 8.0 \mathrm{~GB} \text {, } \\
\text { 9.0 GB, 10.0 GB, 12.0 GB, 14.0 GB, 18.0 GB }\end{array}$ \\
\hline Display size & Any display size (by default), 8", 10", 11", 13", 14", 15" \\
\hline Colour depth & Any colour depth (by default), 8-bit (256), 16-bit (64K), 18-bit, 24-bit (16.7M), 32-bit \\
\hline Resolution & $\begin{array}{l}\text { Any resolution (by default), 1600X1200, 1280X1024, 1024X768, 1024X480, 800X600, } \\
640 \times 480\end{array}$ \\
\hline CD/DVD & Any CD/DVD (by default), none, CD-ROM, DVD-ROM, DVD-R/W \\
\hline OS & $\begin{array}{l}\text { Any OS (by default), MacOS 7, MacOS } 8 \text {, MacOS 9, Windows 2000, Win } 2000 \text { Prof, } \\
\text { Windows 95, Windows 98, Windows NT } 4.0\end{array}$ \\
\hline Input & $\begin{array}{l}\text { Any input (by default), Easy Point III, Easy Point IV, Pointing stick, Touchpad, } \\
\text { TrackPoint }\end{array}$ \\
\hline Colour & Any colour (by default), black, blueberry, grey/graphite, silver, tangerine, white \\
\hline Weight & $\begin{array}{l}\text { Any weight (by default), } 4.0 \mathrm{lb} \text { and under, } 5.0 \mathrm{lb} \text { and under, } 5.5 \mathrm{lb} \text { and under, } 6.0 \mathrm{lb} \text { and } \\
\text { under, } 6.5 \mathrm{lb} \text { and under, } 7.0 \mathrm{lb} \text { and under, } 7.5 \mathrm{lb} \text { and under, } 8.0 \mathrm{lb} \text { and under }\end{array}$ \\
\hline Brand & Any brand (by default), NEC, HP and DELL \\
\hline
\end{tabular}

seven-point rating scales. Each construct is measured using multiple indicators. ${ }^{28}$ Pre-test was conducted to evaluate the performance of the program and the Web server in responding to requests for the experiment pages from outside locations, and to verify that the experimental procedure is understood well and that instructions and questions are clearly labelled and written. A convenience sample consisting of undergraduate students at a mid-western University was used for the pre-test. As a result of Cronbach procedure, some items of the corresponding scales were deleted to improve reliability. Questions in terms of rewording to improve comprehension and eliminate sources of confusion were based on the comments received.

The final items associated with each construct are briefly described in the following section. Figures 1-4 describe the nine items corresponding to the four constructs in the final survey. A summary of the test results is provided in Table 2 .

\section{Willingness to pay for customisation}

Willingness to pay for customisation is measured through directly asking subjects about the perceived worth of customisation. Two-item scales for 'self-perceived customisation worth', and 'perceived fairness on supplier's additional charge on customisation' are developed. These two items are assessed on scales 


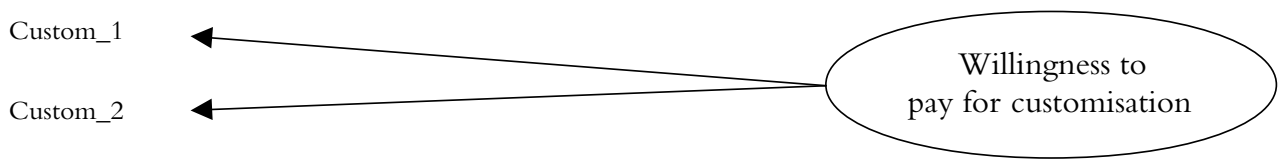

Figure 1 Construct: willingness to pay for customisation

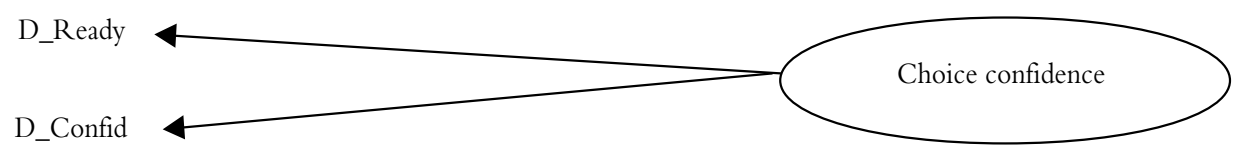

Figure 2 Outcome construct: choice confidence

anchored by 1 and 7. Higher numbers indicated more positive worth and fairness perceived by the subjects. The following are the two final items after subjecting to a measurement purification process (as shown in Figure 1).

Custom_1: Compared to regular price (the average price of those traditional shopping ways, for example, supermarket, catalogue and television), how much more or less are you willing to pay for buying a laptop computer product in the way you have just gone through on previous page?

Custom_2. If the supplier wants to charge an addition over the regular price (the average price of those traditional shopping ways, for example, supermarket, catalogue, and television) for the laptop computer product since they provide the purchase interface of the previous page, how much will that be to make you think fair?

\section{Choice confidence}

In the choice confidence scale, the item measuring 'ready to purchase' ranges from $\mathrm{No} / 10 \% / 30 \% / 50 \% / 70 \% / 90 \%$ to
Yes. The item measuring 'confidence to make a purchase' ranges from 'Not confident at all' to 'Very confident' (as shown in Figure 2).

D_Ready: Now, are you ready to make a purchase?

D_Confid: How confident are you feeling you can make a right purchase now?

\section{Customer anticipated satisfaction}

The following three-item scale is used to measure anticipated satisfaction with the choice. The first item ranges from 'extremely dissatisfied' to 'extremely satisfied'. The second and the third item range from 'strongly disagree' to 'strongly agree' (as shown in Figure 3). A satisfaction index was constructed by getting the factor score of the three items.

SATI_C_1: How satisfied or dissatisfied are you expecting to be with the laptop computer product you chose?

SATI_C_2: I am expecting I will be very displeased with the laptop computer product I purchased.

SATI_C_3: I am expecting that I will be very happy with the laptop computer product I purchased. 


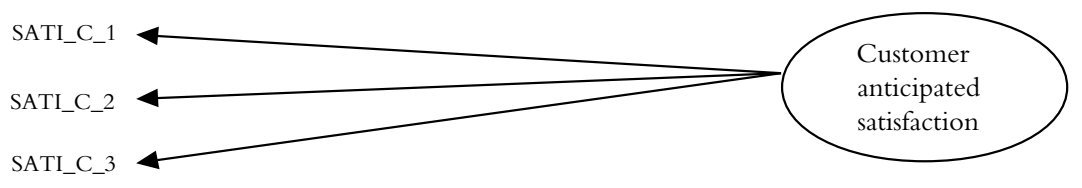

Figure 3 Outcome construct: customer anticipated satisfaction

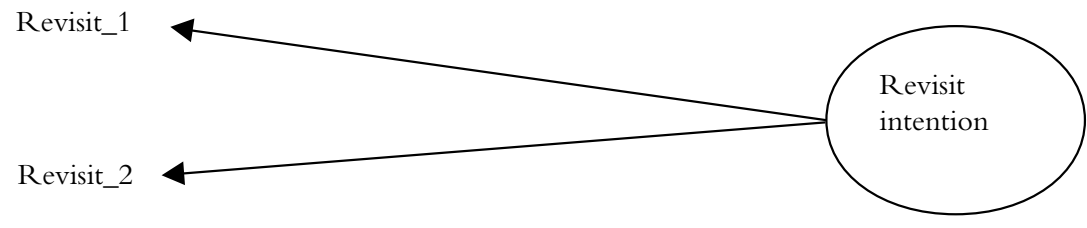

Figure 4 Outcome construct: revisit intention

\section{Revisit intention}

This research operationalises 'revisit intention' as attitudinal, which not only indicates higher repurchase intent, but also willingness to recommend the customisation provider to others. The first item of this scale ranges from 'Not come again' to 'Sure to come'. The second item ranges from 'strongly disagree' to 'strongly agree' (as shown in Figure 4).

Revisit_1: If you want to buy a similar product next time online, how sure you will visit this website.

Revisit_2: I would be happy to recommend my friends to choose from the same set of product options in this site on their next purchase occasions.

\section{EMPIRICAL ANALYSES}

\section{Scale reliability and factor structure}

The final data collected online (total 108 respondents) was examined for violations of normality and outlier contamination so that, if necessary, appropriate data transformations could be executed to correct for abnormal skewness and kurtosis levels. No outlier cases were found and all scales exhibit normal distributions within acceptable tolerances of skewness and kurtosis levels and hence, no transformations were deemed necessary.

All scales used in the research are initially tested for internal consistency using the Cronbach alpha reliability procedure $^{29}$ and examined by means of principal component analysis to reveal the underlying structure and multidimensionality of the scales. ${ }^{30}$ All scales are subjected to principal component analysis with VARIMAX rotation to uncover underlying factor structures. All the scales are found to be unidimensional. Alpha for the four scales and average variance extracted ${ }^{31}$ were all calculated. Table 3 displays descriptive statistics and the reliability results of the proposed scales. The alpha values of the derived measures used in this study were all greater than .70 , demonstrating in general, that the measures are adequate given Nunnally's ${ }^{32}$ standard.

\section{Hypothesis testing}

A one sample $T$-test is used to test $\mathrm{H} 1$ for the scale willingness to pay for customisation. Given the scale for the construct is 1 to 7 , test value is set at 4.0 (the midpoint of the scale) to determine 
Table 2: Results of principal component analyses for the four multiple-item scales

\begin{tabular}{|c|c|c|c|c|}
\hline Scale & $\begin{array}{l}\text { Single-factor } \\
\text { model }\end{array}$ & $\begin{array}{l}\text { Single-factor } \\
\text { model }\end{array}$ & $\begin{array}{l}\text { Single-factor } \\
\text { model }\end{array}$ & $\begin{array}{l}\text { Single-factor } \\
\text { model }\end{array}$ \\
\hline \multicolumn{5}{|l|}{ Willingness to pay for customisation } \\
\hline Explained variance & $77.702 \%$ & & & \\
\hline Eigenvalue of the extracted factor & 1.554 & & & \\
\hline \multicolumn{5}{|l|}{ Component matrix } \\
\hline CUSTOM_1 & 0.881 & & & \\
\hline CUSTOM_2 & 0.881 & & & \\
\hline \multicolumn{5}{|l|}{ Choice confidence } \\
\hline Explained variance & & $89.850 \%$ & & \\
\hline Eigenvalue of the extracted factor & & 1.797 & & \\
\hline \multicolumn{5}{|l|}{ Component matrix } \\
\hline D_CONFID & & 0.948 & & \\
\hline D_READY & & 0.948 & & \\
\hline \multicolumn{5}{|l|}{ Customer anticipated satisfaction } \\
\hline Explained variance & & & $70.906 \%$ & \\
\hline Eigenvalue of the extracted factor & & & 2.127 & \\
\hline \multicolumn{5}{|l|}{ Component matrix } \\
\hline SATI_C_1 & & & 0.926 & \\
\hline SATIIC_2 & & & 0.708 & \\
\hline SATI_C_3 & & & 0.876 & \\
\hline \multicolumn{5}{|l|}{ Revisit intention } \\
\hline Explained variance & & & & $85.697 \%$ \\
\hline Eigenvalue of the extracted factor & & & & 1.714 \\
\hline \multicolumn{5}{|l|}{ Component matrix } \\
\hline C_LOYA_1 & & & & 0.926 \\
\hline C_LOYA_2 & & & & 0.926 \\
\hline
\end{tabular}

whether consumers' willingness to pay for customisation is positive. $\mathrm{H} 1$ is not supported $(t=1.542, P=0.126)$. The result indicates that consumers are not willing to pay extra for customisation per se.

\section{General linear model (GLM) multivariate procedure}

The hypothesised relationships between willingness to pay for customisation and the other three marketing outcome variables were also explored on the basis of data from the Web-based survey. The factor analysis score was taken as an indirect measurement for each construct. Factor scores on choice confidence, customer anticipated satisfaction, and revisit intention were regressed on factor score of willingness to pay for customisation using general linear model (GLM) multivariate procedure. The GLM multivariate procedure provides regression analysis to test null hypotheses about the effects of the independent (predictor) variable of 'willingness to pay for customisation' on multiple dependent variables (choice confidence, customer anticipated satisfaction, and revisit intention). The assumption of using GLM multivariate is the correlation of the dependent measures, which is assessed with Bartlett's test of sphericity. In this study, the approximate chi-square is 145.589 with five degree of freedom and the significance is 0.000 , indicative of a significant level of correlation between the three dependent measures.

Table 4 contains the GLM multivariate results for the effects of willingness to pay for customisation.

As illustrated in Table 4, the independent variable, willingness to pay for customisation, shows highly significant effects for all the multivariate tests. In each instance, the significance level exceeds .000. Moreover, the statistical power is .992 , indicating that large effect size ensured high levels of power with the sample size. 
Table 3: Descriptive statistics for scales

\begin{tabular}{llrll}
\hline Scale & $\begin{array}{l}\text { Number of } \\
\text { items }\end{array}$ & Mean & Std & Coefficient $\alpha$ \\
\hline Willingness to pay for customisation & 2 & 8.299 & 2.006 & 0.716 \\
Choice confidence & 2 & 8.056 & 3.247 & 0.887 \\
Customer anticipated satisfaction & 3 & 14.224 & 3.298 & 0.783 \\
Revisit intention & 2 & 8.243 & 3.168 & 0.830 \\
\hline
\end{tabular}

Table 4: GLM multivariate summary table: the effects of willingness to pay for customisation

\begin{tabular}{|c|c|c|c|c|c|c|c|}
\hline \multicolumn{6}{|c|}{ Multivariate tests of significance } & \multicolumn{2}{|c|}{ Statistical power } \\
\hline Test name & Value & Approx. F & $\begin{array}{l}\text { Hypothesis } \\
\text { df }\end{array}$ & $\begin{array}{l}\text { Error } \\
\text { df }\end{array}$ & $\begin{array}{l}\text { Sig. of F } \\
\text { statistic }\end{array}$ & $\begin{array}{l}\text { Partial eta } \\
\text { squared } \\
\text { (effect size) }\end{array}$ & Power \\
\hline Pillai's trace & 0.197 & 8.428 & 3 & 103 & 0.000 & 0.197 & 0.992 \\
\hline Wilks' lambda & 0.803 & 8.428 & 3 & 103 & 0.000 & 0.197 & 0.992 \\
\hline Hotelling's trace & 0.245 & 8.428 & 3 & 103 & 0.000 & 0.197 & 0.992 \\
\hline Roy's largest root & 0.245 & 8.428 & 3 & 103 & 0.000 & 0.197 & 0.992 \\
\hline
\end{tabular}

In addition to the multivariate analysis using Pillai's trace, Wilks' lambda, Hotelling's trace, and Roy's largest root criterion with approximate $\mathrm{F}$ statistic, GLM multivariate produces estimates of parameters. The estimates of the regression parameters are reported in Table 5 .

There is a positive and significant relationship between the choice confidence and willingness to pay for customisation (Beta $=0.437, p=0.000$ ), $\mathrm{H} 2$ is supported. There is also a positive and significant relationship between consumers' anticipated satisfaction and willingness to pay for customisation $($ Beta $=0.321, p=0.001), \mathrm{H} 3$ is supported. Positive and significant relationship is found between the revisit intention and willingness to pay for customisation as well (Beta $=0.383$, $p=0.000)$, H4 is supported.

Consumers' willingness to pay for customisation was found to be an important explanatory variable for marketing outcome variables in terms of consumers' confidence in making decisions, their anticipated satisfaction and their intention to revisit the customisation provider. In particular, higher willingness to pay for customisation was expected to increase consumer confidence, anticipated satisfaction and intention to revisit. This finding should have important managerial implications for marketers.

The effect of one-to-one targeting on willingness to pay was somewhat complex. Contrary to expectations, the results showed that increased use of one-to-one targeting (eg customisation in this case) in website interfaces does not generate corresponding high willingness to pay for this strategy, even if there is additional value to consumers. Although the research did not provide detailed information about the factors influencing willingness to pay, the finding supports the notion that with respect to one-to-one targeting, other factors may be more important than economic benefits to generate such willingness. Stated differently, these results indicated that although one-to-one targeting provides more value to consumers, consumers' willingness to pay for 
Table 5: Parameter estimates

\begin{tabular}{|c|c|c|c|c|c|c|}
\hline Dependent variable & Parameter & Beta & $\mathbf{t}$ & Sig. & $\begin{array}{l}\text { Partial eta } \\
\text { squared } \\
\text { (effect size) }\end{array}$ & Power \\
\hline Choice confidence & Willingness to pay & 0.437 & 4.980 & 0.000 & 0.191 & 0.999 \\
\hline Customer anticipated satisfaction & Willingness to pay & 0.321 & 3.478 & 0.001 & 0.103 & 0.931 \\
\hline Revisit intention & Willingness to pay & 0.383 & 4.247 & 0.000 & 0.147 & 0.988 \\
\hline
\end{tabular}

customisation might depend mainly on other factors.

\section{ROBUSTNESS OF FINDINGS}

In order to test the robustness of the previous findings, additional data were collected through performing a conceptual replication with another product category, cheese. Most American consumers are highly familiar with cheese, and this product category is being customised at some Internet websites. But cheese and laptop computers differ enormously as products. For instance, the attributes of cheese are primarily sensory (eg flavour), while a laptop computer has non-sensory searchable attributes (eg display size).

The method used in collecting this data set closely matched that used in laptop computer customisation. In the process of customising cheese, subjects were asked to examine carefully as much information as they need about each attribute of milk source, texture, fat content, flavour, beverage, use, style and brands. Two hundred and eight respondents participated in the process by making choices on each of the above attributes to build their own cheese type and filled out a follow-up survey.

The 'willingness to pay for customisation' using 'cheese' was found to be slightly lower than that using 'laptop computer'. A one sample T-test $(t=-0.567, P=0.572)$ indicated this data set also failed to support H1. Such similar findings to those in laptop computer customisation would provide strong support for the notion that consumers are not willing to pay extra for customisation per se.

The hypothesized relationships between willingness to pay for customisation and the other three marketing outcome variables were also supported by this data set using GLM multivariate procedure. The regression parameter estimates (Beta $=0.426$, $p=0.000)$ supported $\mathrm{H} 2$, a positive and significant relationship between the choice confidence and willingness to pay for customisation. H3 was also supported as the regression estimates (Beta $=0.343$, $p=0.000)$ showing a positive and significant relationship between consumers' anticipated satisfaction and willingness to pay for customisation. Positive and significant relationship was found between the revisit intention and willingness to pay for customisation as well (Beta $=0.396, p=0.000)$, therefore supporting $\mathrm{H} 4$.

These findings, as with those of laptop computer customisation, would also suggest that the supported hypothesised relationships between willingness to pay for customisation and three marketing outcome variables are somewhat generalisable across product categories, which would be especially relevant to managers.

\section{CONCLUSION}

The impact of online customisation in the value creation process for consumers may be far reaching. Most authors have 
approached the mass customisation debate from a production-cost viewpoint and seem to argue that prices of customised products are expected to be higher than non-customised products reflecting the higher production costs, but that these prices are falling as technology drives production costs down.

By approaching customisation from a production-cost standpoint these authors have left open the strategic issues involved in the pricing of personalised products. But, from a marketing point of view, pricing which is a result of strategic forces in the market is more interesting than the production-cost approach. Would strategically behaving consumers pay more for customised product in equilibrium? The trade press seems to answer that they would. Most customers are willing to pay a premium (often ten to 50 cents) simply because customised products have greater value than standardised ones and they more closely match each individual's needs. ${ }^{33}$

There is still, however, considerable doubt as to how exactly the value addition will transfer into company's profits. This paper has attempted to shed some light on exploring if consumers are willing to pay for additional benefits brought by customisation. Contrary to expectations, one-to-one targeting (eg customisation) benefits turned out to have no effect on consumers' willingness to pay more. This is consonant with Wind and Rangaswamy's ${ }^{34}$ observation that, 'Levi's and CD Now found out that they could not charge a large premium for customised products'.

Consumers may not always be willing to pay for customisation they consider having positive value. This may be explained by the costs generated by one-to-one targeting that influence the willingness to pay. In such cases, additional economic benefits from customisation may not be a good predictor of willingness to pay for this value addition. In addition, if the competition for providing customisation is high, and consumers are cumulating experience of customising, even the additional value from customisation still exists, or increases, but the willingness to pay for customisation will decrease since customisation at that time will no longer be an effective differentiation strategy.

More interestingly, does such a willingness lead to any positive marketing outcomes? By explicitly addressing this issue, it is possible to uncover some insightful aspects regarding their marketing outcomes as relating to willingness to pay for customisation. In a customisation scenario, consumers more willing to pay for customisation per se would be more confident in their purchase choice, more likely to be satisfied with the chosen product/service, and more likely to revisit the customisation provider.

Not surprisingly, in the market for customised goods, consumers want to remain with the same marketers. By doing so, it may be better for consumers to interact with only one producer (thereby making it a monopoly for supplying their customisation needs) rather than with multiple firms. The consumer prevents the higher input cost for the firm, thus justifying the situation in which consumers can actually benefit from sticking with one marketer for customised goods.

The findings also address the issue of the relationship between consumers and producers, given the paradigm shift from one-way communication to two-way communication that customisation necessarily entails. In traditional markets, there is the widespread belief that the wants and needs of consumers and producers are misaligned. Producers increasingly want to build deep, 
long-lasting ties with consumers. This could have the effect of typing consumers into 'monopolistic relationships'. The growth of various forms of loyalty programmes, which seek to build consumer loyalty towards particular producers, is an example of this trend.

Future research could take further steps in the direction of integrating consumer willingness to pay for customisation into a full market model and into models including the other antecedent factors affecting this variable. Internet-based consumer panels that focus on specific consumption areas combined with figures on their customisation costs may be potential sources of data to conduct such analyses.

Another valuable further theoretical step in this line of research would be to integrate the current consumer model in a market mechanism model that also can capture strategic competitive effects that may occur as part of the dynamics in the supply side of the market. It would be interesting to explore under which competitive scenarios consumers' willingness to pay for customisation or one-to-one targeting will change or not. For example, issues that could be addressed include manufacturers' decisions to introduce Internet-based productions, and market mechanism design for Internet one-to-one targeting to decrease the cost of consumers by engaging in such activity.

\section{References}

1 Hoffman, D. L. and Novak, T. P. (1996) 'Marketing in hypermedia computer-mediated environments: Conceptual foundations', Journal of Marketing, Vol. 60, No. 3, pp. 50-68.

2 Alba, J., Lynch, J., Weitz, B., Janiszewski, C., Lutz, R., Sawyer, A. and Wood, S. (1997) 'Interactive home shopping: Consumer, retailer, and manufacturer incentives to participate in electronic marketplaces', Journal of Marketing, Vol. 61, No. 4, pp. $38-53$.
3 Wind, J. and Rangaswamy, A. (2001)

'Customerization: The next revolution in mass customization', Journal of Interactive Marketing, Vol. 15, No. 1, pp. 13-32.

4 Huffman, C. and Kahn, B. E. (1998) 'Variety for sale: Mass customization or mass confusion', Journal of Retailing, Vol. 74, No. 4, pp. 491-514.

5 Godek, J., Yates, J. F. and Auh, S. (2000) 'Customization decisions: The roles of assortment and consideration', working paper, Ann Arbor, University of Michigan.

6 Ibid.

7 Huffman and Kahn (1998) op cit.

8 Prahalad, C. K. and Ramaswamy, V. (2000) 'Co-opting customer competence', Harvard Business Review, Vol. 78, No. 1, pp. 79-87.

9 Wind and Rangaswamy (2001) op cit.

10 Lazer, W., Labarbera, P., MacLachlan, J. M. and Smith, A. E. (1990) 'Marketing 2000 and beyond', American Marketing Association, New York.

11 Glazer, R. (1991) 'Marketing in an information-intensive environment: strategic implications for knowledge as an asset', Journal of Marketing, Vol. 55, No. 4, pp. 1-19.

12 Huffman and Kahn (1998) op cit.

13 Tversky, A. and Shafir, E. (1992) 'Choice under conflict: The dynamics of deferred decision', Psychological Science, Vol. 6, No. 6, pp. 358-361.

14 Zhang, S. and Sood, S. (1999) 'Option information as the determinant of choice deferral', working paper, UCLA.

15 Beattie, J., Baron, J., Hershey, J. C. and Spranca, M. D. (1994) 'Psychological determinants of decision attitude', Journal of Behavioral Decision Making, Vol. 7, No. 2, pp. 129-144.

16 Huffman and Kahn (1998) op cit.

17 MacInnis, D. J. and Price, L. L. (1987) 'The role of imagery in information processing: Review and extensions', Journal of Consumer Research, Vol. 13, No. 4, pp. 473-491.

18 Christensen, S. (1978) 'Problem solving strategies: A selection mechanism, some implications, and some data', Organizational Behavior and Human Performance, Vol. 22, No. 2, pp. 307-323.

19 Christensen, S. (1980) 'A further examination of the selection of problem-solving strategies: The effects of deadlines and analytic aptitudes', Organizational Behavior and Human Performance, Vol. 25, No. 1, pp. 107-122.

20 Payne, J. W., Bettman, J. R. and Johnson, E. J. (1988) 'Adaptive strategy selection in decision making', Journal of Experimental Psychology, Vol. 14, No. 4, pp. 534-552.

21 Payne, J. W., Bettman, J. R. and Johnson, E. J. (1993) 'The adaptive decision maker', Cambridge University Press, Cambridge, MA.

22 Mills, J., Meltzer, R. and Clark, M. (1977) 'Effect of number of options on recall of information supporting different decision strategies', Personality and Social Psychology Bulletin, Vol. 3, No. 2, pp. 213-218.

23 Simon, H. A. (1955) 'A behavioral model of rational 
choice', Quarterly Journal of Economics, Vol. 59, No. 1, pp. $99-118$.

24 Simon, H. A. (1956) 'Rational choice and the structure of the environment', Psychological Review, Vol. 63, No. 1, pp. 129-138.

25 Huffman and Kahn (1998) op cit.

26 Williamson, O. E. (1985) 'The economic institutions of capitalism: Firms, markets, relational contracting', The Free Press, New York.

27 Godek et al. (2000) op cit.

28 Churchill, G. A. (1979) 'A paradigm for developing better measures of marketing constructs', Journal of Marketing Research, Vol. 16, No. 1, pp. 64-73.

29 Cronbach, L. J. (1951) 'Coefficient alpha and the internal structure of tests', Psychometrica, Vol. 16, No. 2, pp. 297-334.

30 DeVillis, R. F. (1991) 'Scale development, theory and application', Applied Social Research Methods Series, Vol. 26, Sage Publications, Newbury Park.

31 Fornell, C. and Larcker, D. F. (1981) 'Evaluating structural equation models with unobservable variables and measurement error', Journal of Marketing Research, Vol. 18, No. 1, pp. 39-50.

32 Nunnally, J. C. (1978) 'Psychometric theory', 2nd edition, McGraw-Hill, New York.

33 Anderson, D. M. (1997) 'Agile product development for mass customization', McGraw Hill, New York. 34 Wind and Rangaswamy (2001) op cit. 